\title{
Recruiting patients for drug trials: a difficult task
}

\author{
U. Skerritt, B. Pitt, S. Armstrong and A. O'Brien
}

\begin{abstract}
In successtully recrulting patients for drug trials in dementia the Therapeutic Research Unit for the Elderly (TRUE) had referrals from various sources. The local Memory Clinic (MC) provided 38 patients for screening of which 31 (81\%) were recrulted, $75 \%$ of the overall number recrulted. This number was small $(n=41)$ desplite various efforts and does not reflect the time invested and amount of contact work with GPs, out-patient departments and other psychlatic services.

The memory clinic provides a source of recrullment of patients for drug trials as well as services for those who do not quallty for such trials. But recrulting without the aid of a memory clinic is dificicult and timeconsuming and new approaches must be found.
\end{abstract}

Studies of cholinergic therapy for Alzheimer's disease (AD; Chatellier \& Lacomblez, 1990; Eagger et al, 1991) have shown some benefit and studies continue with multi-infarct (MID) and other dementias. Recruitment of patients for such drug trials is important, as is identifying those who might benefit from such drugs, were a licence to be granted.

The elderly population has many problems which make for difficulty in recruitment not found in other populations, for example concomitant physical illness, infirmity, isolation, and polypharmacy (Berg et al, 1982; Levy et ah, 1982). Consequently the net for potential subjects must be cast wide. Attempts to obtain subjects by advertising (Levy et al, 1982), broadcasting (Williams et al, 1988) and age/sex registers (Wilcock et al, 1994) have variable success but the ratio of successful recruits to initial contacts is always low.

\section{The study}

TRUE is based at the Hammersmith Hospital London and recruits patients for drug trials in dementia, both multi-infarct dementia and Alzheimer's disease. The criteria for entry into the trials are strict and exclude patients with MMSE scores of less than 10 and greater than 26 (Folstein et al, 1975), severe physical illness and concomitant use of medication (including antidepressants, neuroleptics and anxiolytics). TRUE seeks referrals from the memory clinic
(MC), OP/DOME (Out-Patients Department of the Elderly) Hammersmith Hospital as well as local GPs and self-referrals. There have also been referrals from Neurology and General Adult Psychiatric services. The unit placed two advertisements in the Alzheimer's Disease Society (ADS) newsletter and also sent 150 letters with referral forms and self-addressed envelope to the GPs.

The Memory Clinic (MC) at the Hammersmith Hospital was established in 1987 (Kelly et al, 1995). It now sees 50 new patients a year from various sources and disciplines including selfreferrals, although a GP's letter is desirable.

As the drug-trials began some time after the MC was set up, there were data on patients seen at the MC who might have been suitable for recruitment. The research sister (SA) examined the case notes of 160 of these patients, some of whom had been seen at the MC up to two years before. To these were added eight current patients: a total of $168 \mathrm{MC}$ patients.

\section{Findings}

The MC provided 168 contacts of which 38 were screened and $31(18.5 \%)$ eventually recruited. The other main diagnostic categories at the MC were: 11 patients $(6.5 \%)$ depressed, and 20 patients who were worried well or with minimal cognitive impairment (11.9\%) (Nicholls, 1995). Ninety-nine patients $(58.9 \%)$ had a diagnosis of dementia but were disqualified before detailed screening for a number of reasons: unable to participate 28; MMSE too low 35; language problems 4; physical illness 21; dementias other than $\mathrm{AD} / \mathrm{MID} 1$; already in trial 3; died 2; too young 5 . There were an additional seven patients with a diagnosis of dementia who were disqualified on screening. The 150 letters to GPs yielded two referrals who were recruited.

The OP/DOME referred six, of whom four were recruited. The ADS newsletter elicited 10 contacts of whom two were recruited and two were recruited from other sources (psychiatrists and neurologists). Overall there were 189 contacts: 59 were screened and $41(21.6 \%)$ recruited. 


\section{Comment}

Although the ratio of $1: 5$ compares favourably with the previous studies, the time and work in obtaining such a sample is great. Licensing of cholinergic anti-dementia drugs would increase GP vigilance due to patient demand.

In our study, the MC provided the largest percentage of the patients recruited $(75 \%)$. The percentage of recruits from a back-log is likely to be less than current cases, for example MMSE scores might have dropped below the cut-off point over the course of two years. As the MC is now working in tandem with the TRUE, we would hope that this will no longer be a problem and referrals from the MC will be even greater. Although 150 letters were sent to GPs, there were only two replies. This is a cause for concern as most of the cases of mild dementia, suitable for drug trials, are in the community and GPs may be the only contact for these patients. The ADS newsletter proved disappointing in that most of the contacts made were unsuitable, either too severely demented or not demented at all.

\section{Representativeness}

With regard to sex distribution and marital status, the sample that attended the memory clinic was comparable to the 1991 census figures available for people of pensionable age in Britain (Office of Population Censuses and Surveys, 1993). Like other memory clinic studies (Philpot \& Levy, 1987) many of the subjects came from social class I or II ( $57 \%$ compared to $25 \%$ in the population). The mean 10 scores for patients attending the $\mathrm{MC}$, in all diagnostic groups, were well above the mean for the general population.

In their paper Kelly et al (1995) conclude that those who attend the MC at the Hammersmith Hospital are "above average intelligence, highly motivated, keen to obtain new treatments and willing to participate in research". In this way they are not representative of the population in general but are probably still the best source of recruitment for such patients.

\section{Workload and time invested}

An aim of a Bristol study was to determine the workload engendered by trying to identify subjects for drug trials from GP surgeries. Wilcock et al (1994) examined a community sample who had no previous screening and although the potential number identified was small the work "was not onerous". The authors suggest that perhaps the best way to identify this population is to incorporate a cognitive screen (MMSE) in the over 75 GP check so that serial scores may be available, identifying those with early dementia who then may be investigated further.
MC patients are seen for 1-2 hours at first appointment, and are then referred for a CT scan. physical examination and blood tests, and language assessment (Stevens et al. 1992). If suitable they are referred to the TRUE where a further screening is carried out, taking about two hours. Patients from other sources are screened by TRUE for 150 minutes after which many are disqualified, often because of use of concomitant medication (antidepressants), low levels of B12 and folate, or atrial fibrillation. A clinical history of Alzheimer's disease but Hachinski score of $>5$ spelled exclusion, while a clinical history suggestive of MID but Hachinski score of $<5$ also meant exclusion.

A MC is more than a source of recruitment for drug trials. It offers a comprehensive multidisciplinary assessment, able to clarify diagnoses often difficult to make in primary care settings. This is highlighted by the high proportion (37\%) of worried well patients (Kelly et al, 1995), many of whom have a family history of dementia (Philpot \& Levy, 1995), referred by GPs indicating the difficulty of excluding a diagnosis of dementia in a patient complaining of memory problems. It also identified those with depression and anxiety (13\%), offered reassurance to the worried well and follow-up to those with AAMI or minimal cognitive impairment.

The successful recruitment rate from the MC is encouraging but in areas that do not have access to a MC, recruitment may be difficult and depend on GPs and local advertisement. Williams et al (1988) sought to encourage potential clients by:

- having available a research nurse who would spend more time examining older patients

- having a research coordinator with special skills in geriatric care available to talk with volunteers and their families by telephone and in person, both before and after their participation in the study to provide information, support and help with referrals

- time spent with those who did not participate or who were disqualified

- allocation of sufficient funds to provide transportation, parking expenses and occasional hospital meals for the relatives or friends.

New approaches to recruitment must be found by increasing and targeting advertising to 'at risk' groups, for example those in residential homes and sheltered housing. However, what is clear is that it is more effective to have patients who are motivated visiting the memory clinic or recruitment centre rather than visiting people in their homes. 


\section{References}

Berg, L. , Hughes, C. P.. CoBen, L. A. et al (1982) Mild senile dementia of the Alzheimer's type: research diagnostic criterla, recruitment and description of study population. Journal of Neurology Neurosurgery and Psychiatry. 46. 962-968.

Chateuner, G. \& LACOMBLEZ, L. (1990) Tacrine (tetrahydroaminoacridine; THA) and leicithin in senile dementia of the Alzhelmer type: a multi-centre trial. Group Francal d'etude de la tetrahydroaminoacridine. Brttish Medical Joumal, 300, 495-499.

EAGGer, S. A. LEVY, R. \& SAHAKan, B. J. (1991) Tacrine in Alzheimer's discase. Lancet, 397, 989-992.

Folsten,. M., Folstein, S. \& McHughS, P. (1975) The "MiniMental State": a practical method for grading the cognittive state of patients for the clinic. Journal of Psychiatric Reseanch, 12, 189-198.

KEUY, C. A., HARVEY, R. J., STEVENS, S. J., et al (1995) Spectalist Memory Clinic: The experience at the Hammersmith Hospital. Facts and Research in Gerontology. 1. 21-30.

LEVY, M., MOHS, R., ROSEN, W., et al (1982) Research subject recruitment for gerontological studies of pharmacological agents. Neurobiological Aging. 3, 77-79.

Nicноц, C. G. (1995) Mild Memory Impairment. Current Opinion in Psychiatry. 8, 258-263.

Ofmce of POPULATION Censuses AND SuRveys (1993) 1991 Census Report for Great Britain. London: HMSO.
PHIPOT, M. P. \& LEVY, R. (1987) A memory clinic for the earty diagnosis of dementia. International Journal of Ceriatric Psychiatry, 2, 195-200.

Stevens, S., PrTt, B., Nichol, C., et al (1992) Language assessment in a memory clinic. International Joumal of Gerlatric Psychiatry, 7, 45-51.

Wncock. G. K., AshwORTH, D. L., LANGField, J. A. et al (1994) Detecting patients with Alzheimer's disease suitable for drug treatment: comparison of three methods of assessment. Brttish Joumal of Ceneral Practice, 44, 40-33.

WiLuas, D. E., Vrmeuno, M. V., Ries, R. K. et al (1988) Successful recruitment of elderly community-dwelling subjects for Alaheimer's disease research. Joumal of Gerontology. 48, 69-74.

*U. Skerritt, Senior Registrar, Park Royal Centre for Mental Health, Acton Lane, London NW10 7NS; B. Pitt, Academic Department of Old Age Psychiatry, St Charles' Hospital, London W10 6DZ; Sally Armstrong, Research Sister, and Anthony O'Brien, Lecturer and Hon. Senior Registrar, Therapeutic Research Unit for the Elderly, Hammersmith Hospital, London

"Correspondence

\section{Speech and Language Disorders in Psychiatry Edited by Andrew Sims}

Descriptive psychopathology provides a different and refreshing approach to the understanding of mental illness. Speech and Language Disorders in Psychiatry starts from this standpoint and links research into speech and language disorder with clinical psychiatry. In particular, it provides a detailed and comprehensive account of current research into schizophrenic speech and language disorder. The authors of this collection of articles are leading authorities in psychiatry, neurology, psychology and communications.

- $£ 20.00 \bullet 206 p p . \bullet H a r d b a c k \bullet 1995 \bullet$ ISBN 0902241796

Available from bookshops and from the Publications

Department, Royal College of Psychiatrists, 17 Belgrave Square,

London SW1X 8PG (Tel. 0171-235 2351 extension 146) 